\title{
SPME-GC-MSD for Determination of Nine Phenyl Compounds in Snow Water in Beijing China
}

\author{
Shan Zhou ${ }^{1,2,3, 凶}$, Junxiong Huang ${ }^{1,2}$, Xing Gao ${ }^{3}$, Liwen Zhao ${ }^{3}$ \\ 'State Key Laboratory of Environmental Chemistry and Ecotoxicology, Research Center for Eco-Environmental Sciences, \\ Chinese Academy of Sciences, Beijing, 100085, China; E-Mail: zhoush@bjcdc.org \\ ${ }^{2}$ Graduate School of Chinese Academy of Sciences, Beiijing, China \\ ${ }^{3}$ Department of Central Laboratory, Beijing Municipal Center for Disease Prevention and Control, No.16, Hepinglizhongjie, Dongcheng District, \\ Beijing, 100013, China ${ }^{\varpi}$ (mailing address)
}

Received: 19 January 2005 / Revised: 31 March 2005 / Accepted: 7 April 2005

Online publication: 15 June 2005

\begin{abstract}
Solid phase microextraction (SPME) then capillary gas chromatography with mass spectrometric detection have been used for determination of nine phenyl compounds in snow water in Beijing City. Headspace extraction with a fiber coated with $100 \mu \mathrm{m}$ PDMS was used to extract the compounds. Extraction and desorption times were optimized at 8 and $2 \mathrm{~min}$, respectively. Relative standard deviation (RSD) of the analytical method was found to be less than $5 \%$. The linear range was wide and limits of detection were less than $5 \mathrm{ng} \mathrm{mL}^{-1}$ for the nine target analytes. Several phenyl compounds at $\mathrm{ng} \mathrm{mL}^{-1}$ levels were detected in snow samples in Beijing, indicating the corresponding air pollution.
\end{abstract}

\section{Keywords}

Gas chromatography-mass spectrometry

Solid phase microextraction

Headspace sampling

Snow water

Phenyl compounds

\section{Introduction}

Determination of phenyl compounds is of great concern because of their high toxicity [1]. Sample pretreatment is routinely required to detect low levels of contaminants in water. Conventional techniques employed to achieve this include liquidliquid extraction (LLE), headspace (HS) extraction, solid-phase extraction (SPE), supercritical fluid extraction (SFE), and purge and trap (PT) [2, 3]. Although these require either high-cost instrumentation or extensive training, and the procedures are cumbersome, time- and labor-consuming, they are often unsuccessful. An alternative method, solid-phase microextraction (SPME) has developed rapidly since it was invented by Pawliszyn and coworkers at the University of Waterloo, Canada in 1989 [4]. This solvent-free technique has numerous advantages, for example simplicity, low-cost, and the possibility of on-line analysis. As a result it has great potential for analysis of volatile organic compounds (VOC) [5-7].

Economic development in China, especially in Beijing, has brought much improvement of people's living standard and greatly stimulated the use of cars. As a consequence, release of exhaust gas from automobiles could worsen air-pol- lution problems already resulting from industrial sources. Although much effort has been made, it is still a challenge to reduce potential adverse effects to a minimum. Phenyl compounds, for example benzene and toluene, are major components of gasoline and can be released to the atmosphere in exhaust gases from automobiles. When it snows they can be brought down to the ground. This study focused on testing of snow samples as an indicator of air pollution by phenyl compounds in Beijing. In this study, a method was established for determination of phenyl compounds in water, and snow water samples were collected in the city of Beijing and analyzed.

\section{Experimental}

\section{Instrumentation and Reagent}

The SPME fiber holder, an SPME fiber coated with $100 \mu \mathrm{m}$ PDMS (polydimethylsiloxane), and heating and stirring equipment were obtained from Supelco. GC6890 and GC-MSD5973 instrumentation were from Agilent Technology. Stock solutions $\left(100.0 \mu \mathrm{g} \mathrm{mL}^{-1}\right)$ of nine phenyl compounds-benzene, toluene, chlorobenzene, ethylbenzene, p-xylene, styrene, isopropylbenzene, $n$-propylbenzene, and 1,2-dichlorobenzene (all from Sigma-Aldrich)—were prepared in this laboratory by weighing and dilution with methanol (HPLC grade). These were diluted with pure 
Table 1. Experimental conditions

\begin{tabular}{ll|} 
HS-SPME extraction & \\
Extraction vial & $20 \mathrm{~mL}$ \\
Sample volume & $10 \mathrm{~mL}$ \\
SPME fiber & $100 \mu \mathrm{m}$ \\
Extraction time & $8 \mathrm{~min}$ \\
Temperature & $30^{\circ} \mathrm{C}$ \\
$G C-M S D$ analysis & \\
Instrument & Agilent 5973 \\
Column & $30.0 \mathrm{~m} \times 0.25 \mathrm{~mm} \times 0.25 \mu \mathrm{m}$ HP5-MS \\
GC oven program & $35^{\circ} \mathrm{C}$ for $5 \mathrm{~min}$, \\
& $3 \mathrm{~min}^{-1}$ to $60^{\circ} \mathrm{C}$, \\
& $8^{\circ} \mathrm{min}^{-1}$ to $180^{\circ} \mathrm{C}$ \\
Inlet temperature & $200^{\circ} \mathrm{C}$ \\
Insert inner diameter & $0.75 \mathrm{~mm}$ \\
Desorption time & $2 \mathrm{~min}$ \\
Temperature & $200^{\circ} \mathrm{C}$ \\
Split ratio & 30 \\
FID temperature & $250^{\circ} \mathrm{C}$ \\
MSD interface & $280^{\circ} \mathrm{C}$ \\
MS scan range & $35-350$ \\
\hline
\end{tabular}

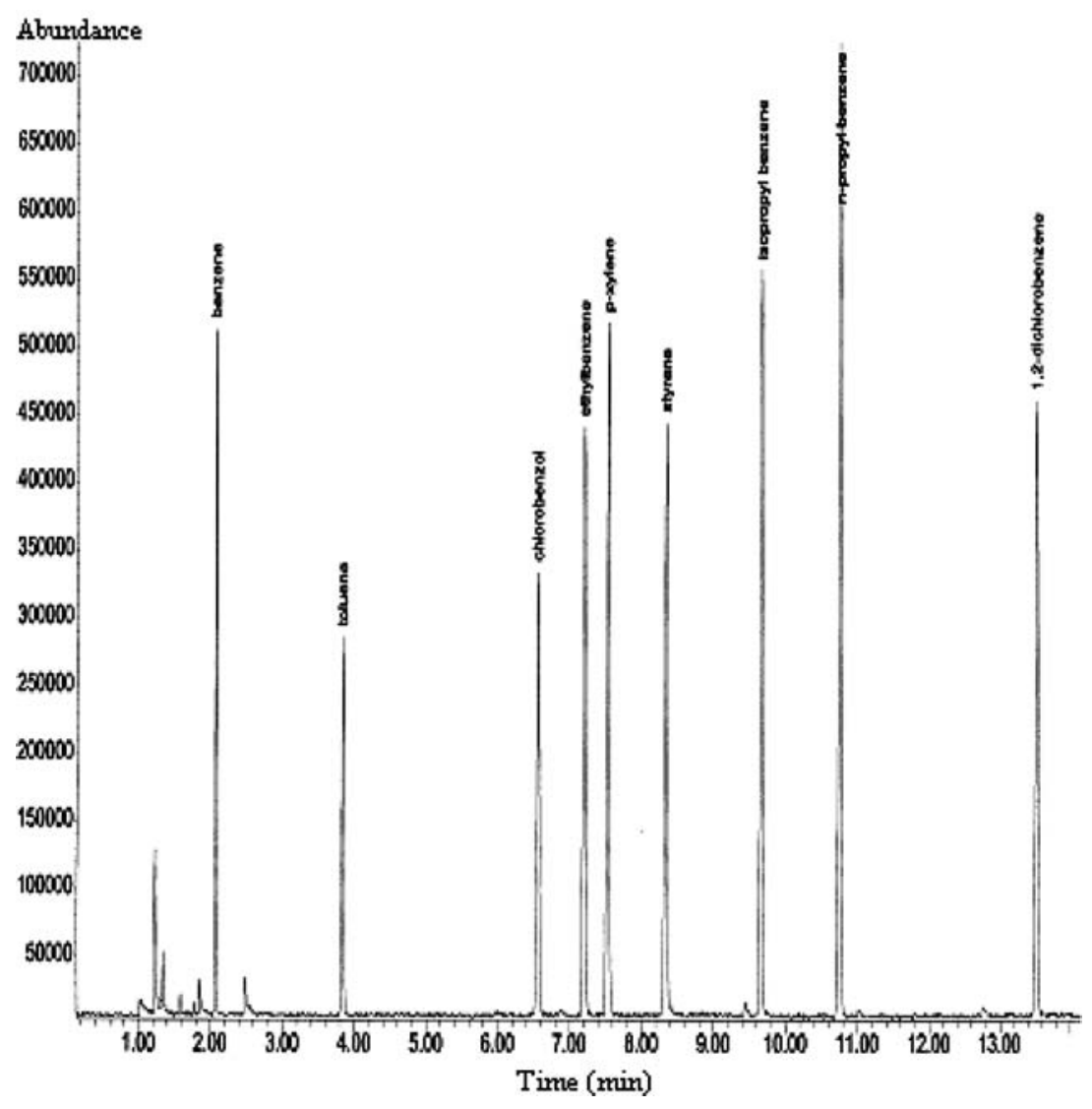

Fig. 1. TIC chromatogram obtained from $50 \mathrm{ng} \mathrm{mL}^{-1}$ mixed standard

water from a Milli-Q system to prepare more dilute solutions.

\section{Sample Collection and Storage}

Triplicate snow samples were collected from each of the four inner city regions of Beijing. All samples were stored in precleaned glass containers and kept at $4^{\circ} \mathrm{C}$ until analysis. Assays were performed within one week of sample collection. Analysis of each sample was performed on $10 \mathrm{~mL}$ melted snow water.

\section{Procedure}

The sample or standard $(10.0 \mathrm{~mL})$ was placed in a $20.0-\mathrm{mL}$ headspace vial, stirred and heated under the conditions selected, the fiber was inserted, and extraction was performed for $8 \mathrm{~min}$. The fiber was then inserted into the injector of the GC and thermally desorbed for 2 min. Compounds were separated on a $30.0 \mathrm{~m}$ HP-5MS capillary column under the temperature conditions listed in Table 1. Both FID and MSD were employed for detection. FID was used for system optimization and method validation and MSD for snow sample analysis and for method development. The analytical conditions used are also listed in Table 1.

\section{Results and Discussion}

\section{Optimization of HS-SPME}

On the basis of the design of the method, SPME extraction time, temperature, stirring speed, and desorption time are believed to affect the efficiency of extraction of the target compounds by the fiber and their subsequent desorption $[8,9]$. It was found that for the most volatile compounds such as benzene and toluene, exposure of the fiber for $4-5 \mathrm{~min}$ is long enough to reach equilibrium. For less volatile analytes, however, for example isopropylbenzene and 1,2-dichlorobenzene, more time was required. For all nine analytes exposure for $8 \mathrm{~min}$ was selected as the optimum extraction time for this study. Because most of the chemical compounds release heat during the absorption process, lower temperature favors extraction, although less of the analytes will be present at the headspace; $20-30^{\circ} \mathrm{C}$ was found to be ideal for this study. Stirring accelerates transport of the analytes from the liquid solution to the headspace and, therefore, to and from the SPME fiber surface. Conventional magnetic stirring and heating equipment was used in our study; it was found that stirring at full-speed favored HS-SPME. Compared with the conditions discussed above, desorption time was found to have less effect and 2 min was eventually selected.

\section{Method Validation}

\section{Qualitative and Quantitative Study}

GC retention time $\left(R_{\mathrm{T}}\right)$ was used to identify the nine target compounds and GC-MSD was used to confirm the identities and for quantitative analysis of the water samples by recording the total-ion 
current (TIC) in scan mode. A typical TIC chromatogram obtained from GCMSD of the nine target compounds is illustrated in Fig. 1.

\section{Linear Range and Limit of Detection (LOD)}

Standard curves were constructed using data obtained from the nine phenyl compounds at appropriate concentrations under the optimized conditions described above. Linear ranges for the nine target compounds are listed in Table 2. Wide linear ranges were obtained and regression data were good. Spiked standard solutions were analyzed and limits of detection ( $L O D)$ and quantitation $(L O Q)$, respectively, were calculated as 3 and 10 times the signal-to-noise ratio $(S / N)$. It was found that $L O D$ of the target compounds were in the range 0.3 to $3.0 \mathrm{ng} \mathrm{mL}-1$ and $L O Q$ were in the range 1.0 to $10.0 \mathrm{ng} \mathrm{mL}^{-1}$. Related data are given in Table 2 .

\section{Precision and Recovery}

Under controlled conditions water samples were spiked with $30.0 \mathrm{ng} \mathrm{mL}^{-1}$ standard solutions of the nine compounds and were analyzed twelve times. Relative standard deviations ( $R S D, \%$ ) calculated for all analytes were below $5 \%$. When water samples spiked with 10.0 and $30.0 \mathrm{ng} \mathrm{mL}^{-1}$ standards were analyzed six times average recovery was found to be 85 to $107 \%$.

\section{Levels of the Phenyl Compounds in Snow Water, and Environmental Implications}

Results obtained from analysis of snow samples are listed in Table 3. Of the nine compounds investigated benzene and toluene were present at the highest levels; concentrations ranged from 37.4 to $621.1 \mathrm{ng} \mathrm{mL}^{-1}$. $p$-Xylene, styrene, and isopropylbenzene were present at levels of several ng $\mathrm{mL}^{-1}$ and chlorobenzene, ethylbenzene and $n$-propylbenzene were not detectable under our experimental conditions. Benzene and toluene seemed to be the main phenyl pollutants among the nine compounds tested and probably arise automobile exhaust gases and, possibly, industrial sources. Levels of both benzene and toluene were highest in the

Table 2. $L O D, L O Q$, and linear range for the nine target compounds

\begin{tabular}{|lllll|}
\hline Compound & $\begin{array}{l}\text { Linear range } \\
\left(\mathrm{ng} \mathrm{mL}^{-1}\right)\end{array}$ & $R^{2}$ & $\begin{array}{l}\text { LOD } \\
\left(\mathrm{ng} \mathrm{mL}^{-1}\right)\end{array}$ & $\begin{array}{l}L O Q \\
\left(\mathrm{ng} \mathrm{mL}^{-1}\right)\end{array}$ \\
\hline Benzene & $10.0-70.0$ & 0.9970 & 3.0 & 10.0 \\
Toluene & $5.0-70.0$ & 0.9983 & 2.0 & 5.0 \\
Chlorobenzene & $5.0-70.0$ & 0.9990 & 2.0 & 5.0 \\
Ethylbenzene & $5.0-70.0$ & 0.9980 & 2.0 & 5.0 \\
$p$-Xylene & $2.0-50.0$ & 0.9994 & 0.5 & 2.0 \\
Styrene & $2.0-50.0$ & 0.9988 & 0.5 & 2.0 \\
Isopropylbenzene & $2.0-50.0$ & 0.9996 & 0.3 & 1.0 \\
$n$-Propylbenzene & $2.0-50.0$ & 0.9995 & 0.5 & 2.0 \\
1,2-Dichlorobenzene & $2.0-70.0$ & 0.9993 & 0.3 & 1.0 \\
\hline
\end{tabular}

Table 3. Levels of phenyl compounds in snow water $\left(X_{\mathrm{Avg}} \pm S D\right.$, ng mL $\left.\mathrm{L}^{-1}\right)$

\begin{tabular}{|lclll|}
\hline & South city & East city & West city & North city \\
\hline Benzene & $621.1 \pm 31.1$ & $491.0 \pm 28.5$ & $398.7 \pm 32.7$ & $329.6 \pm 20.8$ \\
Toluene & $69.0 \pm 6.0$ & $54.1 \pm 3.8$ & $37.4 \pm 2.6$ & $43.0 \pm 3.3$ \\
Chlorobenzene & $\mathrm{ND}$ & $\mathrm{ND}$ & $\mathrm{ND}$ & $\mathrm{ND}$ \\
Ethylbenzene & $\mathrm{ND}$ & $\mathrm{ND}$ & $\mathrm{ND}$ & $\mathrm{ND}$ \\
$p$-Xylene & $5.04 \pm 0.60$ & $4.81 \pm 0.50$ & $\mathrm{ND}$ & $4.06 \pm 0.36$ \\
Styrene & $2.80 \pm 0.27$ & $3.20 \pm 0.35$ & $\mathrm{ND}$ & $3.17 \pm 0.31$ \\
Isopropylbenzene & $3.79 \pm 0.49$ & $2.21 \pm 0.20$ & $1.87 \pm 0.18$ & $2.10 \pm 0.25$ \\
$n$-Propylbenzene & $\mathrm{ND}$ & $\mathrm{ND}$ & $\mathrm{ND}$ & $\mathrm{ND}$ \\
1,2-Dichlorobenzene & $6.16 \pm 0.57$ & $16.5 \pm 0.79$ & $2.11 \pm 0.18$ & $8.15 \pm 0.59$ \\
\hline
\end{tabular}

$X_{\mathrm{Avg}}$ is the average concentration from triplicate analysis of each sample

$\mathrm{SD}$, standard deviation

$\mathrm{ND}$, not detectable

south of the city; this was reasonable, because the sampling site was close to the south 3 rd ring road on which there was a heavy flow of automobiles which could release more exhaust gas. Similar to the situation in the south of the city, the sampling site in the east of the city was also in an area with heavy traffic, so levels of both benzene and toluene were higher here than in the north and west regions. There was also an organic chemical plant nearby and concentrations of 1,2-dichlorobenzene reached $16.5 \mathrm{ng} \mathrm{mL}^{-1}$ in the east of the city, at least twice as high as in the other three regions. Although the west of the city has some industrial plants, these mostly produce inorganic chemicals, which did not lead to higher levels of phenyl compounds, levels of which were found to be similar to those in the north of the city. Similar amounts of $p$-xylene, styrene, and isopropylbenzene were detected in snow water from all four regions of Beijing.

\section{Conclusion}

SPME has many good features, for example simplicity, rapidity, and sensitivity; it is also solvent-free. It combines extraction, concentration, and injection in one technique and is easily coupled with GC and GC-MSD. The whole process can be completed within 10 to $20 \mathrm{~min}$, and it was found to be a satisfactory technique for analysis of water samples. Levels of the phenyl compounds found in snow samples in Beijing reflect current air-pollution conditions; more action should be taken to improve the quality of the atmosphere in Beijing.

\section{References}

1. Knox RC, Canter LW (1996) Water Air Soil Pollut 88:205-226

2. Arthur C, Pawliszyn J (1990) Anal Chem 62:2145-2148

3. Zhang Z, Yang M, Pawliszyn J (1994) Anal Chem 66(17):844A-852A

4. Pawliszyn J, Potter D (1992) J Chromatogr 625:247

5. Eisert R, Levsen K (1996) J Chromatogr 733(1/2):143-145

6. Jiu AI (1998) Anal Chem 70(22):4822-4826

7. Huang JX (1997) Hua Xue Jin Zhan (Chinese Magazine) 9(2):179-191

8. Smaele TD, Moens L, Sandra P, Dams R (1999) Mikrochim Acta 130:241

9. Poerschmann J, Kopinke FD, Pawliszyn J (1997) Environ Sci Technol 31:362 